\title{
Fungos causadores de ferrugens (Pucciniales) em plantas da Reserva Florestal Adolpho Ducke, Amazônia Central, Brasil
} Rust fungi (Pucciniales) in plants of the Adolpho Ducke Forest Reserve, Central Amazon, Brazil

\author{
Aline Carvalho de Carvalho ${ }^{1}$, Helen Maria Pontes Sotão $o^{2,4}$ \& Isadora Fernandes de França ${ }^{3}$
}

\begin{abstract}
Resumo
Este trabalho apresenta as espécies de fungos Pucciniales que ocorrem parasitando plantas em uma área de floresta do bioma Amazônia, localizada na Reserva Florestal Adolpho Ducke (RFAD), em Manaus (AM), Brasil. Dezessete espécies foram identificadas: Aecidium annonae, A. amazonense, A. juruense, A. xylopiae, Crossopsora piperis, Desmella aneimiae, Dietelia duguetiae, Edythea palmaea, Porotenus biporus, P. memorae, Puccinia bambusarum, P. heliconiae, P. thaliae, Sphenospora smilacina, Uredo borreriae, U. maceiensis e U. pusilla. Todas representam primeiro registro para a área de estudo. A lista inclui novos registros para o Brasil (U. pusilla), para a região Amazônica (D. duguetiae) e para o estado do Amazonas (A. annonae, A. xylopiae, C. piperis, E. palmaea, P. biporus e $S$. smilacina). Espécies de ferrugem foram registradas em 17 gêneros e 12 famílias botânicas (Annonaceae, Arecaceae, Bignoniaceae, Euphorbiaceae, Fabaceae, Heliconiaceae, Marantaceae, Piperaceae, Poaceae, Rubiaceae, Smilacaceae e Tectariaceae). Na família Annonaceae ocorreram cinco espécies de ferrugem, e na família Bignoniaceae ocorreram duas e para as Pucciniales destas duas famílias foi elaborada uma chave de identificação. São apresentadas descrições, distribuição geográfica, comentários taxonômicos e ilustrações para os novos registros para o Brasil e Amazônia. Palavras-chave: bioma Amazônia, Pucciniomycetes, Basidiomycota, taxonomia.
\end{abstract}

\begin{abstract}
This work presents the Pucciniales fungi species found as parasites of plants in a forest area of the Amazon biome located in the Adolpho Ducke Forest Reserve (ADFR) in Manaus (AM), Brazil. Seventeen species were identified and all represent the first record for the study area. They were Aecidium annonae, A. amazonense, A. juruense, A. xylopiae, Crossopsora piperis, Desmella aneimiae, Dietelia duguetiae, Edythea palmaea, Porotenus biporus, P. memorae, Puccinia bambusarum, P. heliconiae, P. thaliae, Sphenospora smilacina, Uredo borreriae, $U$. maceiensis and $U$. pusilla. All represent the first record for the field of study. The list includes new records for Brazil (U. pusilla), for the Amazon region (D. duguetiae) and for the state of Amazonas (A. annonae, A. xylopiae, C. piperis, E. palmaea, P. biporus and S. smilacina). Rust species were recorded in 17 genera and 12 families of plants (Annonaceae, Arecaceae, Bignoniaceae, Euphorbiaceae, Fabaceae, Heliconiaceae, Marantaceae, Piperaceae, Poaceae, Rubiaceae, Smilacaceae e Tectariaceae). Five rust species occurred on members of the family Annonaceae, and two species on Bignoniaceae; an identification key was created for the Pucciniales fungi found on these two families. Descriptions, geographical distributions, taxonomic comments, and illustrations for the new records for Brazil and for the Amazon are provided.
\end{abstract}

Key words: Amazon biome, Pucciniomycetes, Basidiomycota, taxonomy.

\section{Introdução}

As ferrugens de plantas são doenças causadas por fungos fitopatogênicos da ordem Pucciniales. É um grupo monofilético, classificado no filo Basidiomycota, subfilo Pucciniomycotina e classe
Pucciniomycetes, cujas espécies apresentam os ciclos de vida complexos, podendo apresentar até seis tipos de esporos diferentes (Aime et al. 2006). São parasitas obrigatórios e apresentam alta especificidade de hospedeiros, sendo capazes de infectar um grande

\footnotetext{
${ }^{1}$ Universidade Federal Rural da Amazônia, Prog. Pós-graduação em Ciências Biológicas, Av. Tancredo Neves 2501, Terra Firme, 66077-830, Belém, PA, Brasil. aline.carvalho11@yahoo.com

${ }^{2}$ Museu Paraense Emílio Goeldi, Coord. Botânica, Av. Perimetral 1901, Terra Firme, C.P. 399, 66040-170, Belém, PA, Brasil.

${ }^{3}$ Universidade Federal do Pará, Campus Universitário de Altamira, Faculdade de Ciências Biológicas, R. Coronel José Porfírio 2515, Esplanada do Xingú, 68372-040, Altamira, PA, Brasil. isa_bio@yahoo.com.br

${ }^{4}$ Autor para correspondência: helen@museu-goeldi.br
} 
número de plantas vasculares, cultivadas ou silvestres (Cummins \& Hiratsuka 2003).

Este grupo de fungos constitui uma das maiores ordens do reino Fungi, com cerca de 8.000 espécies descritas (Cummins \& Hiratsuka 2003). Para o Brasil são conhecidas cerca de 750 espécies de Pucciniales, entre estas, 184 são conhecidas para a Região Norte com registros para os estados do Acre (19); Amapá (54), Amazonas (66); Pará (115); Rondônia (1); Roraima (3) e Tocantins (3) (Carvalho-Jr \& Sotão 2016).

Embora a distribuição desses fungos seja cosmopolita, Berndt (2012) sustenta que a riqueza de espécies de ferrugens é determinada pela disponibilidade de plantas hospedeiras, ou seja, a riqueza de ferrugens é influenciada pela composição taxonômica da flora vascular de uma determinada região. Zuluaga et al. (2008) consideram que o estudo da biota de ferrugens pode ser empregado como uma ferramenta promissora em análises biogeográficas, devido a este endemismo de gêneros e espécies do grupo em certas regiões, podendo a presença destes fungos servirem como padrão de comparação em estudos ambientais.

A Reserva Florestal Adolpho Ducke (RFAD) é uma unidade de conservação (UC) localizada no município de Manaus, no estado do Amazonas, em uma área limítrofe ao perímetro urbano, sofrendo forte impacto ambiental com a expansão da Região Metropolitana de Manaus (PELD 2015). É uma das UCs melhor estudadas da Amazônia brasileira e as pesquisas desenvolvidas têm contribuído significativamente para o entendimento da dinâmica ecológica da Amazônia (Oliveira et al. 2008). Entre estes estudos, destacam-se os de Oliveira et al. (2008) e Hopkins (2005), que registram a ocorrência de várias famílias de plantas com potencial ao parasitismo por espécies de ferrugens. Porém, até o momento não havia referência anterior de fungos Pucciniales parasitando plantas na RFAD.

Este trabalho teve por objetivo inventariar os fungos Pucciniales da RFAD e associa-los às plantas hospedeiras, assim como indicar as novas ocorrências, descrever e ilustrar os novos registros para o Brasil e Amazônia.

\section{Material e Métodos}

O inventário foi realizado na Reserva Florestal Adolpho Ducke (RFAD), que abrange uma área de aproximadamente $100 \mathrm{~km}^{2}\left(03^{\circ} 00^{\prime} 00^{\prime \prime}-\right.$ $03^{\circ} 08^{\prime} 00^{\prime \prime}$ S e $59^{\circ} 52^{\prime} 40^{\prime \prime}-59^{\circ} 52^{\prime} 00^{\prime \prime} \mathrm{W}$ ) (Ribeiro 1976). Está situada no divisor de águas de duas principais bacias de drenagem: Rio Amazonas e o Rio Negro. O clima da região segue o tipo Afi de Köppen, com temperatura média de $26^{\circ} \mathrm{C}$ (mínima $19^{\circ} \mathrm{C}$ e máxima $39^{\circ} \mathrm{C}$ ). A precipitação anual varia de 1.900 a $2.300 \mathrm{~mm}$, sendo a estação chuvosa de dezembro a maio e a estação seca de junho a novembro. Apresenta uma cobertura vegetal típica de floresta tropical úmida de terra firme da Amazônia ou Floresta Densa (PELD 2015).

Foram analisadas amostras de fungos causadores de ferrugens procedentes de coleções realizadas pelos autores na RFAD, nos períodos de fevereiro de 2006 e junho de 2015, cuja metodologia adotada para coleta, preservação e herborização foram as referidas por Cummins \& Hiratsuka (2003) e França \& Sotão (2009). Os espécimes foram identificados com base nas famílias das plantas hospedeiras, em análises das microestruturas dos fungos, comparações com espécimes depositadas em herbários (MG e IAN) e bibliografia especializada.

Para a etapa de análises morfológicas das microestruturas fúngicas, as técnicas utilizadas foram de Cummins \& Hiratsuka (2003) e França et al. (2010), onde lâminas semipermanentes de soros e esporos foram montadas entre lâmina e lamínula em uma solução de lactoglicerol, posteriormente aquecida e observada sob microscopia óptica (MO). Para se obter as medidas máxima e mínima foram mensurados 20 esporos em média, dos espécimes estudados.

Foi utilizada a microscopia eletrônica de varredura (MEV) para análise detalhada da superfície dos esporos de algumas ferrugens, conforme a metodologia adotada por França \& Sotão (2009).

Literatura especializada com chaves de identificação e descrições de espécies foram consultadas, como Hennen \& Ono (1978), Buriticá \& Hennen (1980), Hennen \& Sotão (1996), Berndt et al. (2002), Cummins \& Hiratsuka (2003), Hennen et al. (2005), Salazar-Yepes \& Carvalho-Jr (2010) e Berndt \& Beenken (2013).

As amostras botânicas foram identificadas com a colaboração de taxonomistas e técnicos (parabotânicos) do Museu Paraense Emílio Goeldi (MPEG).

Os espécimes estudados foram incorporados no herbário João Murça Pires (MG) do Museu Paraense Emílio Goeldi (MPEG).

A nomenclatura utilizada está de acordo com o glossário apresentado por Salazar-Yepes \& Carvalho-Jr (2010). A classificação para família e gêneros dos fungos está de acordo com Cummins \& Hiratsuka (2003). 


\section{Resultados e Discussão}

A partir de estudos taxonômicos realizados com 51 espécimes de ferrugens coletadas na RFAD, foram identificadas 17 espécies de fungos da ordem Pucciniales (Tab. 1), classificados em nove gêneros. Destes, sete são gêneros teleomorfos pertencentes a cinco famílias: Phakopsoraceae (Crossopsora), Pucciniaceae (Puccinia), Pucciniosiraceae (Dietelia), Raveneliaceae (Sphenospora) e Uropyxidaceae (Desmella, Edythea e Porotenus), e dois são gêneros anamorfos: Aecidium e Uredo.

Todas as espécies identificadas representam primeiro registro para a área de estudo. Novos registros foram observados: para o Brasil, a espécie Uredo pusilla F. Kern, Thrust. \& Whetzel sobre Machaerium sp.; para a Amazônia brasileira a espécie Dietelia duguetiae (Thrust.) Buriticá \& J.F. Hennen sobre Duguetia sp. e para o estado do Amazonas, Aecidium annonae Henn. sobre Bocageopsis sp., A. xylopiae Henn sobre Xylopia sp., Crossopsora piperis Berndt, F.O. Freire \& C.N. Bastos sobre Piper sp., Edythea palmaea (J.F. Hennen \& Y. Ono) Cummins \& Y. Hirats sobre Attalea sp., Porotenus biporus J.F. Hennen \& Sotão sobre Adenocalymma sp. e Sphenospora smilacina Syd. sobre Smilax sp.

Os espécimes de plantas hospedeiras registradas neste estudo foram classificados em 17 gêneros, inseridos em 12 famílias vegetais (Tab. 1), 11 da divisão Magnoliophyta e somente uma Pteridophyta (Tectariaceae). Entre as espécies identificadas não foi observada nenhuma ocorrência de um mesmo estádio esporífero em mais de uma família vegetal, evidenciando a característica de especificidade desses fungos até para a categoria de família de hospedeiros, conforme já citado em literatura por diversos especialistas como em Cummins \& Hiratsuka (1983, 2003), Hennen et al. (2005) e Salazar-Yepes \& Carvalho-Jr (2010).

O maior número de espécimes registrados foi de P. biporus (17), parasitando plantas da família Bignoniaceae, do gênero Adenocalymma. Segundo Hopkins (2005), esta é uma das famílias de lianas mais diversas na área de estudo. $\mathrm{O}$ gênero de planta hospedeira Adenocalymma (Bignoniaceae), foi o único que registrou duas espécies de ferrugem $(P$. biporus e P. memorae).

A família de plantas melhor representada foi Annonaceae, com cinco gêneros parasitadas por cinco espécies de ferrugens, seguida por Bignoniaceae. Para estas famílias são apresentadas chaves de identificação com as espécies encontradas na área de estudo. O gênero Bocageopsis
(Annonaceae) foi registrado pela primeira vez como hospedeiro de Aecidium annonae.

\section{Novos registros para o Brasil e Amazônia}

Uredo pusilla F. Kern, Thurst. \& Whetzel, Monograph Univ. Puerto Rico, Series B 2:296 1934. (?/?,IIe/?).

Figs 1a-c

Tipo: sobre Machaerium humboldtianum Vogel (Fabaceae), Venezuela, Carabobo, Adjuntas, Trompillo, ravine. Chardon e Toro, Aug. 14, 1932.

Uredínio abaxial, disperso, arredondado, pequeno, aderido ao tecido da planta, de cor marrom castanho; paráfise periférica, numerosa, cilíndrica, acuminada ou arredondada no ápice, (35-)44-90 × 6-9 $\mu \mathrm{m}$, com 1 septo; parede hialina, uniforme, com 1,5-2 $\mu \mathrm{m}$ de espessura; urediniósporo elipsóide, obovóide ou piriforme, 19-26 × 13-19 $\mu \mathrm{m}$; parede equinulada, hialina, com 1-1,5 $\mu \mathrm{m}$ de espessura, poros obscuros.

Material examinado: BRASIL. AMAZONAS: Manaus, Reserva Florestal Adolpho Ducke, sobre Machaerium leiophyllum var. leiophyllum (DC) Benth, 23.VI.2015, fl., A. Carvalho et al. A2015-39 (MG 217844).

Sobre o gênero Machaerium (Fabaceae), três espécies de Uredo são descritas, U. machaerii Dietel, U. machaeriicola Cummins e U. pusilla, esta última diferencia-se das demais espécies por apresentar paráfise septada, com parede entre 1,5-2 $\mu \mathrm{m}$, enquanto que U. machaerii não apresenta paráfise (Dietel 1897) e $U$. machaeriicola apresenta paráfise sem septo e com parede engrossada (4-7 $\mu \mathrm{m})$ (Cummins 1943).

No Brasil, sobre Machaerium, havia apenas o registro de U. machaerii, em Niterói (RJ).

No presente trabalho é realizado o primeiro registro da espécie no Brasil, anteriormente conhecido somente para a Venezuela (Kern et al. 1934).

Dietelia duguetiae (Thurst.) Buriticá \& J.F. Hennen, Fl. Neotropica 24:17. 1980. (0/?,?/III).

Figs. 1d-i

Basiônimo: Endophylloides degueliae Thurst, Mycologia 32(3): 293 (1940)

Tipo: Duguetia furfuracea (A. St-Hil.) Benth. \& Hook. (Annonaceae), Brasil, Minas Gerais, Uberlândia, 18 Maio 1936, Muller s.n.

Espermogônios adaxiais formando pequenas galhas nas folhas em manchas amareladas, cor preta; télio abaxial com perídio firme, de cor marrom escura; células peridiais rombóides a angulares, $24-34 \times 16-20 \mu \mathrm{m}$; parede externa radialmente estriada e interna verrugosa, com 2-4 


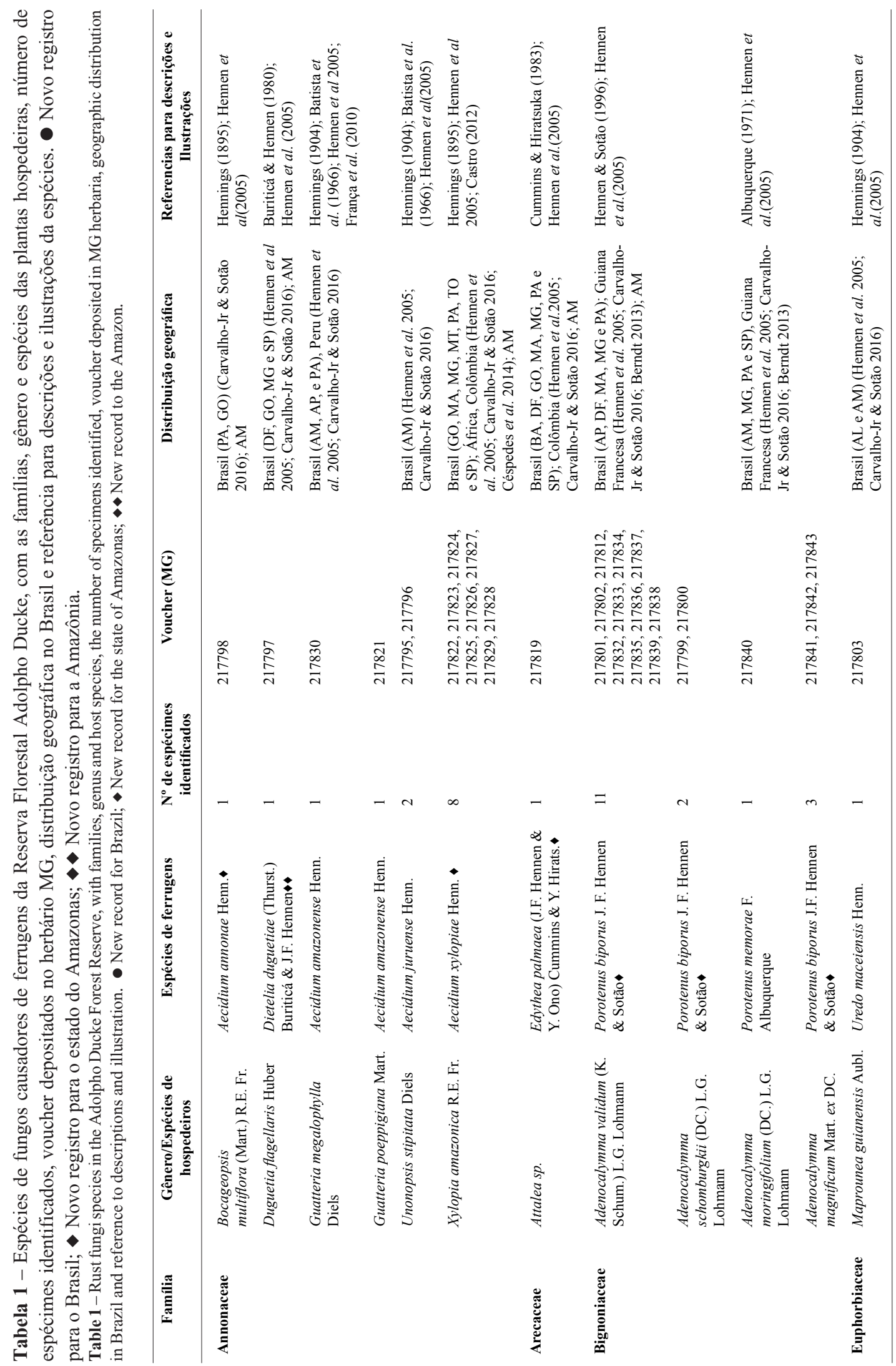




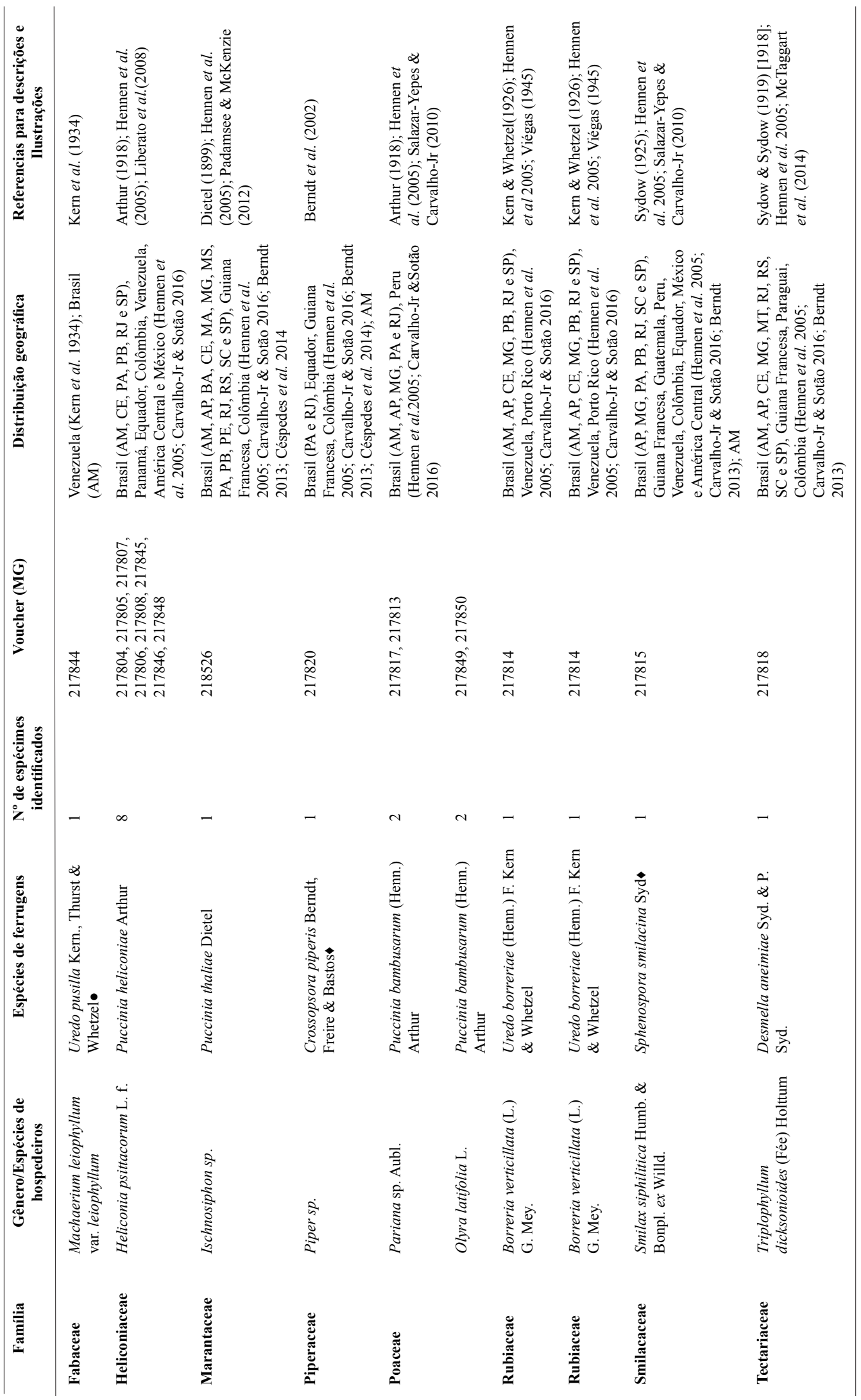



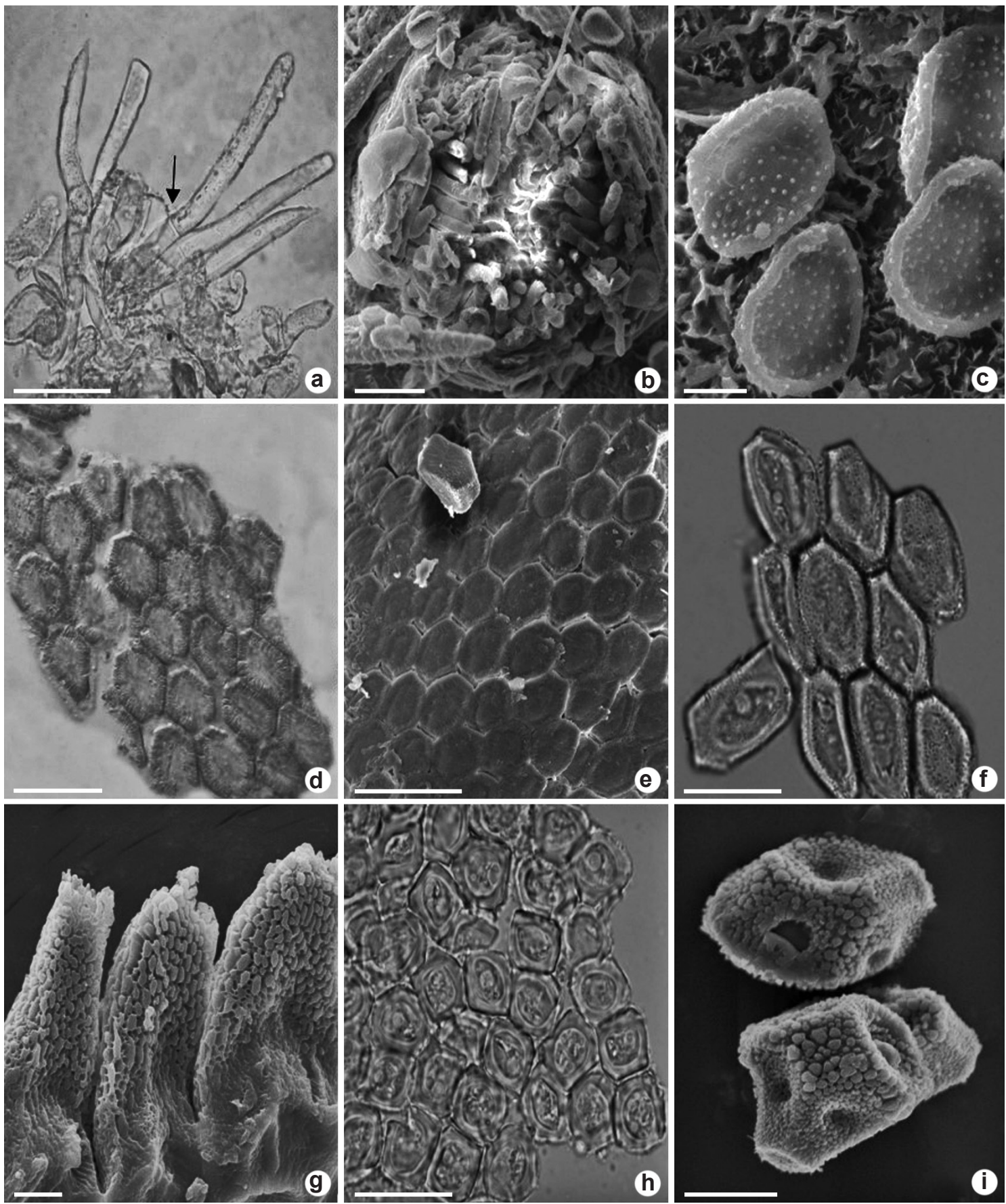

Figura 1 - a-c. Uredo pusilla - a. paráfises periféricas septadas (seta) em MO; b. uredínio, com paráfises periféricas e urediniósporos em MEV; c. urediniósporos com parede equinulada, em MEV. d-i. Dietelia duguetiae - d-e. parede externa das células peridiais radialmente estriada em M.O. e MEV, respectivamente; $\mathrm{f}$-g. parede interna das células peridiais verrugosa em M.O. e MEV, respectivamente; h-i. teliósporos em M.O. e MEV, respectivamente. Barra das escalas: $\mathrm{a}, \mathrm{d}, \mathrm{f}, \mathrm{h}=20 \mu \mathrm{m} ; \mathrm{b}=32 \mu \mathrm{m} ; \mathrm{c}=6 \mu \mathrm{m} ; \mathrm{e}=30 \mu \mathrm{m} ; \mathrm{g}=6 \mu \mathrm{m} ; \mathrm{i}=7 \mu \mathrm{m}$.

Figure 1 - a-c. Uredo pusilla - a. septate peripheral paraphyses (arrow) in MO; b. uredinia with peripheral paraphyses and urediniospores in SEM; c. urediniospores with echinulate wall in SEM. d-i. Dietelia duguetiae - d-e. outer wall radially striated peridial cells in M.O. and SEM, respectively; f-g. inner wall of verrucose peridial cells M.O. and SEM; h-i. outer wall of teliospores in M.O. and SEM, respectively. Scale bar a, d, f, $\mathrm{h}=20 \mu \mathrm{m} ; \mathrm{b}=32 \mu \mathrm{m} ; \mathrm{c}=6 \mu \mathrm{m} ; \mathrm{e}=30 \mu \mathrm{m} ; \mathrm{g}=6 \mu \mathrm{m} ; \mathrm{i}=7 \mu \mathrm{m}$. 
$\mu \mathrm{m}$ de espessura, hialina; teliósporos catenulados amplamente elipsóides a globóides, 14-25 × 11-16 $\mu \mathrm{m}$; parede com faixa irregular verrugosa, com 1-1,5 $\mu \mathrm{m}$ de espessura, com grânulos refrativos bem desenvolvidos.

Material examinado: BRASIL. AMAZONAS: Manaus, Reserva Florestal Adolpho Ducke, sobre Duguetia flagellaris Huber, 4.II.2006, fl., I. França et al. I200630 (MG217797).

A espécie $D$. duguetiae se caracteriza por apresentar télios com perídio persistente formando galhas nas folhas em pequenas manchas, parede externa das células peridiais radialmente estriada e interna verrugosa.

Hennen et al. (2005) citam duas espécies de Pucciniales sobre o gênero Duguetia para o Brasil: Aecidium dugettiae Har. e D. duguetiae (Thurst.) Buriticá \& J.F. Hennen. Estas duas espécies são facilmente confundidas, e a germinação de esporos permite a distinção entre os dois táxons. Estes autores propõem algumas característica que auxiliam na distinção morfológica entre estes dois táxons. D. duguetiae promove a formação de galhas na face adaxial da folha, possui um ciclo de vida microcíclico (0 e III), os télios são abaxiais, profundamente inseridos no tecido foliar, com perídio firme e persistente que fica imerso (não fica exposto), e parede das células peridiais e teliósporos ornamentados. Em $A$. dugettiae há a formação de manchas foliares (não forma galhas), os télios são desconhecidos, são observados apenas espermogônio (0) e écios (I) com perídio e parede das células peridiais e eciósporos lisos (Saccardo 1925; Hennen et al. 2005). Buriticá \& Hennen (1980) e Hennen et al. (2005), apresentam uma discussão dos trabalhos e sinonímias de $D$. duguetiae.

Esta espécie está referida em Hennen et al (2005) e Carvalho-Jr \& Sotão (2016) para o Brasil, nas regiões do Centro Oeste (DF, GO) e Sudeste (MG e SP). Este trabalho representa o primeiro registro para a Região Norte no bioma Amazônia.

\section{Chave de identificação das espécies de Pucciniales em Annonaceae na RFAD}

1. Télio com perídio; écio ausente; formando galhas nas folhas em pequenas manchas; parede externa das células peridiais radialmente estriada; sobre Duguetia Dietelia duguetiae

1'. Télio ausente; écio com perídio, catenulado e verrugoso; formando largas manchas nas folhas; parede externa das células peridiais verrugosa, verrugosa estriada ou lisa; sobre outros gêneros de Annonaceae 2

2. Eciósporos com parede engrossada no ápice $(3-6 \mu \mathrm{m})$, sobre Unonopsis ..... Aecidium juruense

2'. Eciósporos com parede uniforme, sobre outros gêneros de plantas 3

3. Parede externa das células peridiais irregularmente verrugosa estriada; eciósporos com bandas irregularmente verrugosas e áreas lisas entre as bandas; sobre Xylopia .... Aecidium xylopiae

3. Parede externa das células peridiais não estriada; eciósporos com parede verrugosa e sem áreas lisas; sobre Guatteria ou Bocageopsis .. 4

4. Parede externa das células peridiais lisa na parte superior e finamente verrugosa na parte inferior; eciósporos com parede verrugosa, com dois padrões de esporos, pigmentados (amarelo-dourado) com parede finamente verrugosa e esporos hialinos com parede fortemente verrugosa; sobre Guatteria Aecidium amazonense

4'. Parede externa das células peridiais uniformemente e finamente verrugosa; eciósporos hialinos com parede densamente e diminutamente verrugosa, sobre Bocageopsis

Aecidium annonae

Para a região Neotropical 16 espécies de Pucciniales (anamorfos e teleomorfos) estão registradas sobre gêneros da família Annonaceae (Hennen et al. 2005; Berndt 2013; Céspedes et al. 2014; Carvalho-Jr \& Sotão 2016): Aecidium amazonense Henn., A. annonae Henn., A. duguetiae Har., A. guatteriae Dietel, A. huallagense Henn, A. juruense Henn., A. xylopiae Henn., Cerotelium xylopiae Buriticá \& J.F. Hennen, Dasyspora gregaria (Kunze) Henn., Dietelia duguetiae (Thurst.) Buriticá \& J.F. Hennen, Hennenia ditelia Buriticá, Phakopsora crucis-filii (Dianese, R. B. Medeiros \& L.T.P. Santos) Beenken, $P$. neocherimoliae Buriticá \& J. F. Hennen, P. pardocardonae Buriticá, P. pistila (Buriticá \& J.F. Hennen) Beenken e Uredo rolliniae W.T. Dale, 
parasitando gêneros como Annona, Duguetia, Guatteria, Rollinia, Unonopsis e Xylopia.

Muitas destas espécies produzem sintomas similares e são difíceis de serem diferenciadas pelas descrições que têm sido publicadas. Produzem largas manchas hipertrofiadas nas folhas, inicialmente amarelada a marrom-amarelada, com espermogônios em forma de pontos pretos adaxiais. Posteriormente, estas manchas tornam-se enegrecidas e crostosas, estendendo-se transversalmente de um a vários centímetros. A ornamentação da parede das células peridiais pode ser verrugosa, verrugosa-estriada ou verrugosa-labirintiforme, sendo esta a principal característica morfológica utilizada para diferencialas (Hennen et al. 2005). Dependendo do recurso que se utiliza (MO ou MEV), assim como o corante ou clareador, a observação do tipo de ornamentação da parede das células peridiais e eciósporos, em relação às descrições existentes, são bem confusas para serem analisadas e comparadas.

Com base na semelhança entre as espécies do gênero Aecidium descritas em literatura, algumas espécies foram sinonimizadas por Hennen et al. (2005), visando determinar uma identificação mais prática, porém estes advertem que estudos taxonômicos são necessários para melhor diferenciá-las.

Estudos mais recentes, como os de Beenken \& Berndt (2010), Beenken et al. ( 2012), Beenken (2014) e Beenken \& Wood (2015), com ferrugens sobre gêneros da família Annonaceae, usando caracteres morfológicos e análise molecular inseridos na sistemática e filogenia destas ferrugens, tem contribuído para um melhor entendimento dessas espécies. As espécies e espécimes tropicais ainda precisam de estudos com bases morfológicas e moleculares, para elucidar as relações taxonômicas destes táxons, principalmente as espécies dos gêneros Aecidium e Dietelia. Devido à dificuldades para a extração de DNA dos espécimes tipos herborizados destes gêneros, novas coleções nas áreas tropicais de procedência dos mesmos, são necessárias para subsidiar estes estudos taxonômicos.

\section{Chave de identificação das espécies de Pucciniales sobre Bignoniaceae na RFAD}

1. Urediniósporos com um poro germinativo próximo ao hilo na parte convexa, parede equinulada com uma área lisa na parte côncava, $23-31 \mu \mathrm{m} \times 25-30 \mu \mathrm{m}$ Porotenus memorae

1'. Urediniósporos com dois poros germinativos equatoriais, parede equinulada com duas áreas lisas, uma no lado côncavo e outra no lado convexo, 30-40 × 25-30 $\mu \mathrm{m}$ Porotenus biporus

No Brasil são referidas cerca de sete gêneros de ferrugens teleomórficas parasitando espécies da família Bignoniaceae (Crossopsora, Dipyxis, Phakopsora, Phragmidiella, Porotenus, Prospodium e Uropyxis) e mais quatro gêneros anamórficos (Aecidium, Macabuna, Malupa e Uredo), parasitando cerca de 21 gêneros desta família, incluindo os gêneros Adenocalymma e Memora (Hennen et al. 2005).

Recentemente, Lohmann \& Taylor (2014) publicaram uma reorganização da família Bignoniaceae. Entre os vários gêneros taxonomicamente revisados com base em análise morfológica e molecular de vários táxons da tribo Bignonieae (Bignoniaceae), o gênero Memora tornou-se sinônimo de Adenocalymma. Sobre o gênero Memora estão citadas as espécies: Porotenus bibasiporulus J.F. Hennen \& Sotão, Porotenus biporus J.F. Hennen \& Sotão, Porotenus concavus Viégas, Porotenus memorae F.C. Albuq. e Uredo amapaensis J.F. Hennen e Sotão (Hennen \& Sotão 1996; Carvalho-Jr \& Sotão 2016). Dessa forma, se torna necessário uma atualização dos nomes válidos para as plantas hospedeiras de todas as ferrugens publicadas sobre o gênero Memora.

Sobre o gênero Adenocalymma no Brasil, também estão referidas duas espécies de Phragmidiella (P. minuta e P. paulista), que tem seus teliósporos diferenciados dos de Porotenus por serem unicelulares, sésseis e catenulados (Hennen et al. 2005), enquanto que em Porotenus os teliósporos são bicelulares e pedicelados. Já os uredínios dessas espécies de Phragmidiella podem ser diferenciados dos de Porotenus e Uredo, principalmente por apresentarem paráfises, que são ausentes nesses dois gêneros e presentes nos soros de Phragmidiella.

Hennen \& Sotão (1996) apresentam uma chave de identificação que diferenciam as cinco espécies sobre Memora (atualmente 
Adenocalymma). Tendo como base a localização dos poros germinativos e padrão de ornamentação da parede dos urediniósporos e eciósporos.

\section{Agradecimentos}

Ao MPEG a infraestrutura disponibilizada nos laboratórios e Herbário MG; ao MCTIC e ao $\mathrm{CNPq}$, o apoio financeiro as excursões de campo, através do Programa de Biodiversidade da Amazônia (MPEG/INPA/MPEG) e SISBIOTA/ CNPq coordenado pela Dra. Leonor Costa Maia (UFPE); à Dra. Maria Aparecida de Jesus, Dra. Noemia Kazue Ishikawa e Msc. João Vitor Camargo Soares, do INPA, o valoroso apoio na realização das excursões a RFAD; ao parabotânico Luís Carlos Lobato do MPEG a identificação botânica das plantas hospedeiras. A primeira autora agradece ao Curso de Mestrado em Botânica Tropical (Universidade Federal Rural da Amazônia - UFRA/ MPEG), o apoio oferecido e ao CNPq, a bolsa concedida.

\section{Referências}

Aime MC, Matheny PB, Henk DA, Frieders EM, Nilsson RH, Piepenbring M, McLaughlin DJ, Szabo LJ, Begerow D, Sampaio JP, Bauer R, Weiß M, Oberwinkler F \& Hibbett D (2006) An overview of the higher level classification of Pucciniomycotina based on combined analyses of nuclear large and small subunit rDNA sequences. Mycologia 98: 896-905.

Beenken L \& Berndt R (2010) Rust fungi on Annonaceae: the genus Sphaerophragmium. Mycologia 102: 650-663.

Beenken L, Zoller S \& Berndt R (2012) Rust fungi on Annonaceae II: the genus Dasyspora Berk. \& M.A. Curtis. Mycologia 104: 659-681.

Beenken L (2014) Pucciniales on Annona (Annonaceae), with special focus on the genus Phakopsora. Mycological Progress 13: 791-809.

Beenken L \& Wood AR (2015) Puccorchidium and Sphenorchidium, two new genera of Pucciniales on Annonaceae related to Puccinia psidii and the genus Dasyspora. Mycological Progress 14: 49.

Berndt R, Freire F \& Bastos CN (2002) Crossopsora piperis, a new rust species from Brazil. Mycotaxon 83: 266.

Berndt R (2012) Species richness, taxonomy and peculiarities of the neotropical rust fungi: are they more diverse in the Neotropics? Biodiversity and Conservation 21: 2299-2322.

Berndt R (2013) First catalogue of the rust fungi of French Guiana, northern South America. Mycological Progress 12: 193-211.
Berndt R \& Beenken L (2013) Chaconia heliconiae and C. clusiae sp. novae from French Guiana with notes on the genus Chaconia (Uredinales/Pucciniales) in the neotropics. Mycological Progress 12: 397-401

Buriticá P \& Hennen JF (1980) Pucciniosiraceae (Uredinales, Pucciniaceae). Flora Neotropica Monographia 24: 17.

Carvalho-Jr AA \& Sotão HMP (2016) Pucciniales in Flora do Brasil 2020 em construção Jardim Botânico do Rio de Janeiro. Disponível em $<$ http://www.reflora. jbrj.gov.br/reflora/floradobrasil/FB25>. Acesso em 21 fevereiro 2016.

Céspedes PB, Yepes MS \& Pardo-Cardona VM (2014) Pucciniales (Fungi), Royas de Colombia. Revista Facultad Nacional de Agronomia, Medellín 67 (Supl. I): 1-93.

Cummins GB (1943) Descriptions of tropical rusts-v. Bulletin of the Torrey Botanical Club 70: 68-81.

Cummins GB \& Hiratsuka Y (1983) Illustrated genera of rust fungi. APS Press, St Paul. 152p.

Cummins GB \& Hiratsuka Y (2003) Illustrated genera of rust fungi. $3^{\text {rd }}$ ed. APS Press, St Paul. 225p.

Dietel P (1897) Uredo machaerii. Hedwigia 36: 36.

França IF \& Sotão HMP (2009) Novos registros de Ferrugens (Uredinales) sobre Fabaceae para o Brasil. Acta Botanica Brasilica 23: 860-863.

França IF, Sotão HMP \& Costa-Neto SV (2010) Fungos causadores de ferrugens da Reserva Biológica do Lago do Piratuba, Amapá, Brasil. Rodriguésia 61: 211-221.

Hennen JF \& Ono Y (1978) Cerradoa palmae. Mycologia 70: 570 .

Hennen JF \& Sotão HMP (1996) New species of Uredinales on Bignoniaceae from Brazil. Sida 17: 173-184.

Hennen JF, Figueiredo MB, Carvalho Jr AA \& Hennen PG (2005) Catalogue of plant rust fungi (Uredinales) of Brazil. Disponível em <http://www.jbrj.gov.br>. Acesso em 30 novembro 2014.

Hopkins MJG (2005) Flora da Reserva Ducke, Amazonas, Brasil. Rodriguésia 56: 9-25.

Kern F, Thruston HW \& Whetzel HH(1934) Uredo pusilla. Monograph Universidad Puerto Rico, Series B 2: 296.

Lohmann LG \& Taylor CMA (2014) New generic classification of Tribe Bignonieae (Bignoniaceae). Annals of the Missouri Botanical Garden 99: 348-489.

Oliveira ML, Baccaro FB, Braga-Neto R \& Magnusson WE (2008) Reserva Ducke: a biodiversidade amazônica através de uma grade. $2^{\text {a }}$ ed. INPA, Manaus. 160p.

PELD - Pesquisas Ecológicas de Longa Duração (2015) Pesquisas Ecológicas de Longa Duração. Disponível em<http://www.peld.inpa.gov.br/sitios/ducke>. Acesso em 20 novembro 2015.

Ribeiro MNG (1976) Aspectos climatológicos de Manaus. Acta Amazonica 6: 229-233. 
Saccardo PA (1925) Aecidium duguetiae. Sylloge Fungorum XXIII: 868.

Salazar-Yepes MS \& Carvalho-Jr AA (2010) Ferrugens: diversidade de Uredinales do Parque Nacional do Itatiaia, Brasil. Technical Books, Rio de Janeiro. 201p.
Zuluaga C, Buriticá P \& Marín M (2008) Generalidades de los uredinales (Fungi: Basidiomycota) y de sus relaciones filogenéticas. Acta Biológica Colombiana 14: 41-56.

Editor de área: Dr. Mauricio Salazar-Yepes Artigo recebido em 30/09/2016. Aceito para publicação em 14/06/2017. This is an open-access article distributed under the terms of the Creative Commons Attribution License. 